\title{
HYDROTHERMAL ONE-ELECTRON OXIDATION \\ OF CARBOXYLIC ACIDS \\ IN THE PRESENCE OF IRON OXIDE MINERALS
}

\section{SUPPORTING INFORMATION}

\author{
Kristin N. Johnson-Finn*a,b, Lynda B. Williams ${ }^{c}$, Ian R. Gould ${ }^{b}$, Hilairy E. Hartnett ${ }^{\mathrm{b}, \mathrm{c}}$, and \\ Everett L. Shock ${ }^{\mathrm{b}, \mathrm{c}}$ \\ ${ }^{a}$ Earth-Life Science Institute, Tokyo Institute of Technology, Tokyo 152-8550, JAPAN. \\ Correspondence: knjohnson.finn@gmail.com \\ ${ }^{\mathrm{b}}$ School of Molecular Sciences, Arizona State University, Tempe, AZ, 85287, USA \\ ${ }^{\mathrm{c}}$ School of Earth \& Space Exploration, Arizona State University, Tempe, AZ, 85287, USA
}

Below is the supporting information for supplemental experiments performed in support of the results presented in the corresponding study. Figures are called out in corresponding order in the main text. Experiments pictured are as follows: an isotopically labeled phenylacetic acid experiment in the presence of magnetite (Fig. S1), a 50:50 mixture experiments of phenylacetic acid with benzoic acid in the presence of magnetite in comparison to an experiment of phenylacetic acid with magnetite (Fig. S2), an experiment of 2-phenylacetophenone with magnetite (Fig. S3), and a comparison of chromatograms for hydrocinnamic acid without mineral, with magnetite, with hematite, respectively (Fig. S4). 


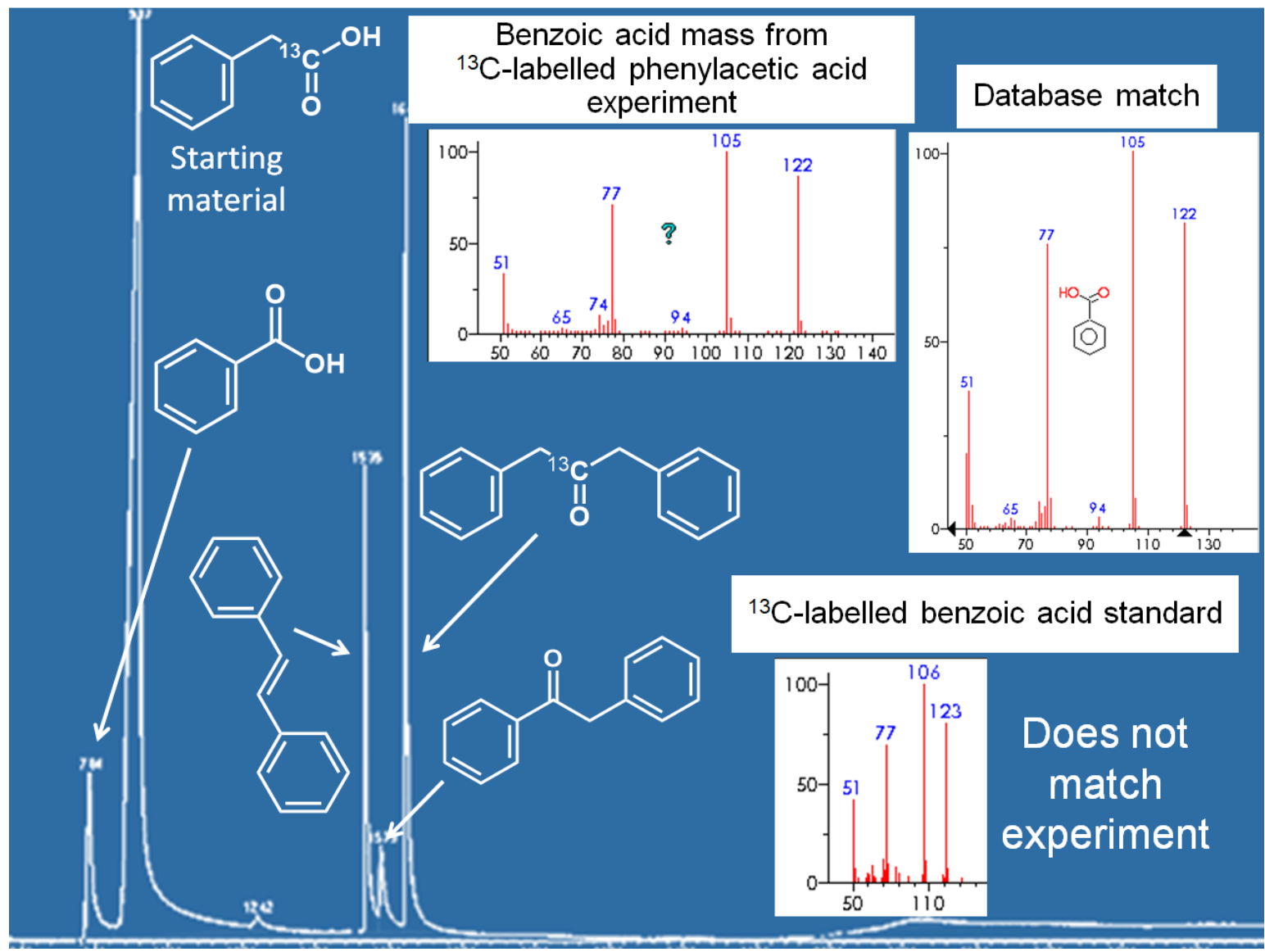

Fig. S1: GC-MS (gas chromatography mass spectrometry) of a ${ }^{13} \mathrm{C}$-labelled PAA experiment with magnetite $\left(\mathrm{Fe}_{3} \mathrm{O}_{4}\right)$ at hydrothermal conditions. The TIC is pictured in blue and white with product peaks labelled by structure. In the experiment with magnetite, the benzoic acid mass fragmentation pattern matches the fragmentation pattern for an unlabeled benzoic acid molecule. To compare, ${ }^{13} \mathrm{C}$-carbonyl labeled benzoic acid was run as a standard. The fragmentation pattern for the labeled benzoic acid standard does not match the fragmentation pattern of the experimentally formed benzoic acid. 

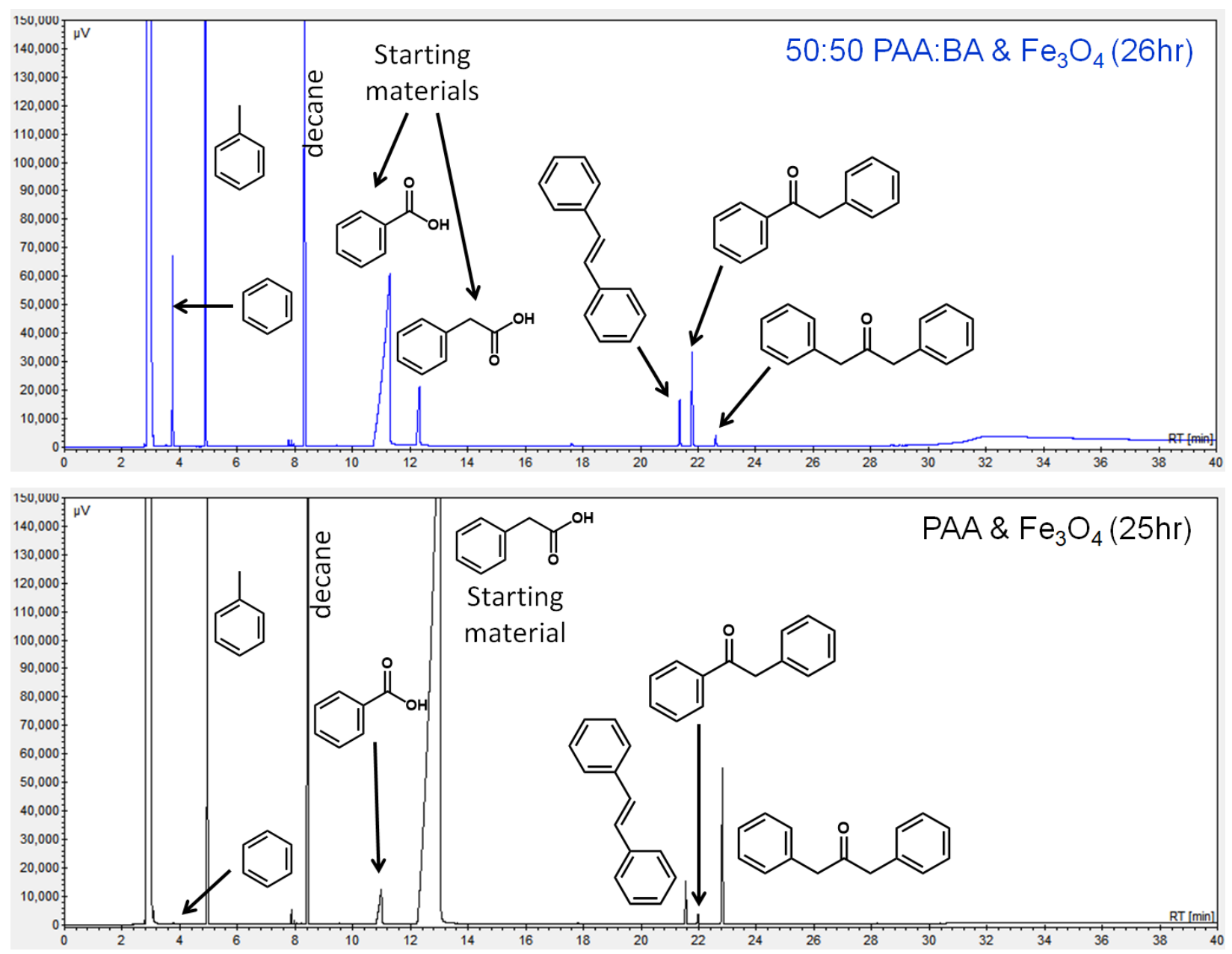

Fig. S2: An experiment beginning with a 50:50 mixture of benzoic acid (BA) and phenylacetic acid (PAA) in the presence of magnetite demonstrated increased formation of 2phenylacetophenone compared to an experiment of PAA and magnetite at a similar timescale. Decane was used as internal standard. 


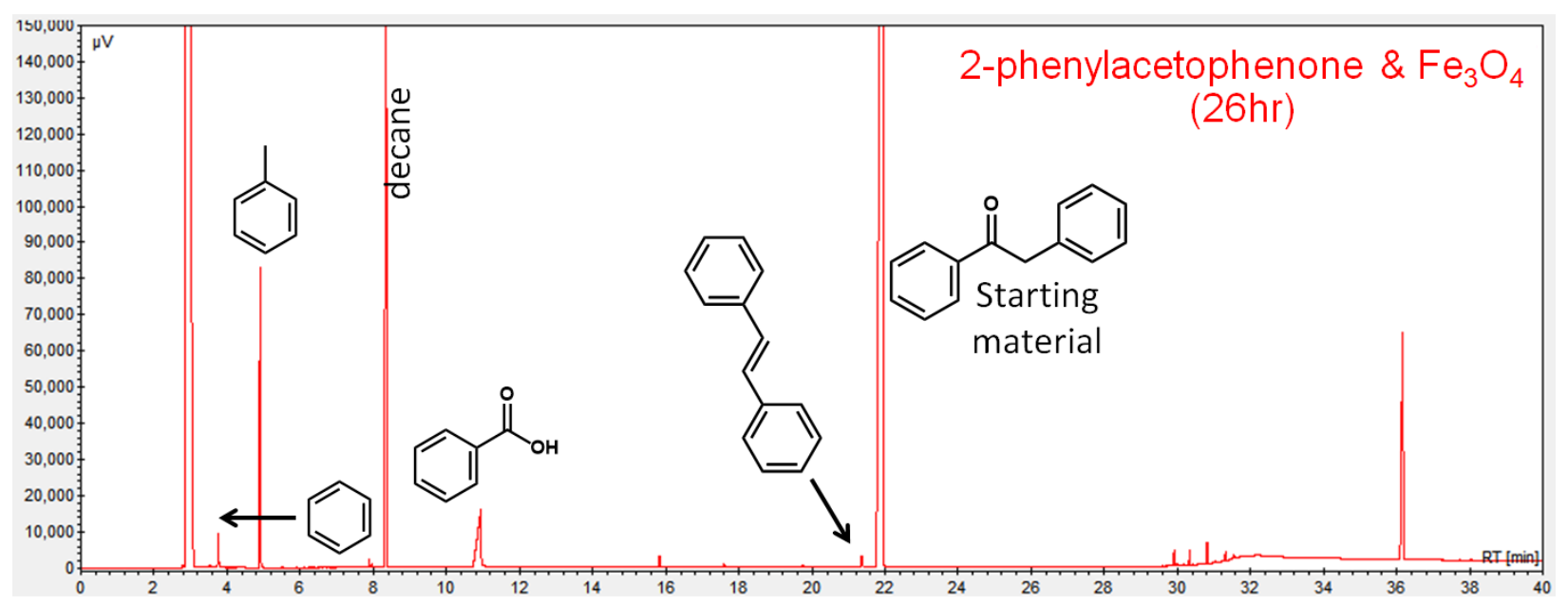

Fig. S3: In experiments starting with 2-phenylacetophenone, the formation of benzoic acid and trans-stilbene were detected. Phenylacetic acid was not observed (expected retention time of 12.5 minutes). The peak seen at around 36 minutes is likely the formation of a 3-ring or 4-ring product of the ketone. Such products have been observed in the case of dibenzylketone (Yang et al. 2012). Decane was used as internal standard. 

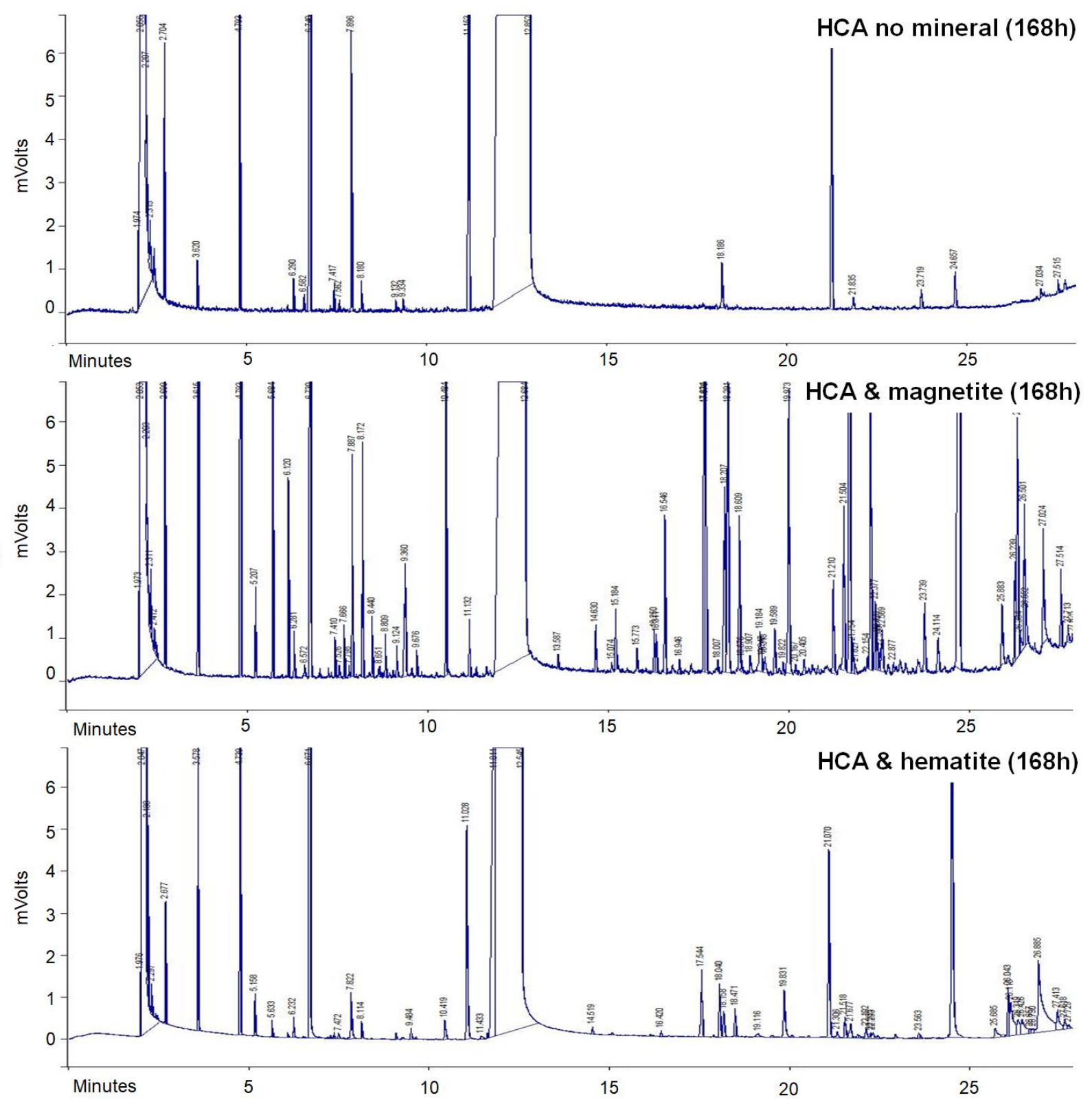

Fig. S4: Gas chromatograms from GC-FID (gas chromatography flame ionization detector) analysis of hydrocinnamic acid (HCA) experiments with or without iron oxide minerals. The chromatogram for $\mathrm{HCA}$ with magnetite $\left(\mathrm{Fe}_{3} \mathrm{O}_{4}\right)$ demonstrates the many additional products formed during the reaction as compared to the chromatogram where no mineral was present during the experiment. Many of the peaks are overlapping and small in intensity, making identification difficult or impossible. For comparison, experiments of HCA with hematite $\left(\mathrm{Fe}_{2} \mathrm{O}_{3}\right)$ result in few product peaks than the experiment with magnetite. 